\title{
Eubacterium ventriosum
}

National Cancer Institute

\section{Source}

National Cancer Institute. Eubacterium ventriosum. NCI Thesaurus. Code C86389.

A genus of aerobic, Gram-positive, rod shaped bacteria assigned to the phylum Firmicutes. This species is non- spore forming, produces hydrogen, and ferments mannose, but not salicin or cellobiose. E. ventriosum is commensal to the human digestive tract. 